\title{
TEACHING READING TO THE CEREBRAL PALSIED CHILD
}

\author{
E. M. HARRISON \\ Johannesburg Srhool and Treatment Centre for Cerebral Palsied Children
}

It is generally accepted that the normal child, from the age of six years is ready for reading, as a result of the spontaneous accumulation of informal experiences, but the Cerebral Palsied child, because of brain damage has usually a reduced ability to spontaneously grasp the basic essentials of learning - be it reading, writing or arithmetic. Therefiore, the building up of the foundations on which learning develops is a primary requirement of the greatest importance, and the teacher must plan a programme of carefully graded experiences and activities to give the child as solid a foundation as possible. In order to be able to plan a "readiness" programme, the teacher must appreciate and fully understand the Cerebral Palsy problem, entailing physical handicaps, learning difficulties and emotional disturbances, all of which occur in varying degrees, as no two children are alike. An initial assessment of each child by the Doctor, Psychologist, Speech, Occupational and Physio Therapists is essential, so that with this initial knowledge and a still more detailed assessment gained as the programme is carried out, special attention is paid to the problems of each individual to enable him to gain the maximum benefit at his own rate of progress, and within his capabilities. This consideration of the developmental level of the child is most important, and the stages of development in the normal child are used as a guide. Thus, the period in which each child achieves "readiness" will vary, and there is no set age at which the Cerebral Palsied child may be said to be ready for reading. If, however, throughout the "reading readiness" programme and the reading scheme, the child is made aware of, and develops a positive attitude towards his abilities and disabilities, with emphasis on the abilities, the confidence gained should ensure that there will be a real desire to read and that his first reader will present no problems.

The following are some of the many contributory factors which cause the lack of "reading readiness" in the Cerebral Palsied child.

1) Physical handicaps.

2) Lack of experience and background.

3) A seeming lack of initiative to use opportunity even when experience and background are present

4.) Emotional disturbances.
5) Visual and auditory perception and spatial concept difficulties; tactile and kinaesthetic sensory losses; visuo-motor lack; short attention and memory span; distractibility; speech involvement and hearing loss.

\section{THE READING READINESS PROGRAMME FOR THE NURSERY AND KINDERGARTEN GROUPS RESPECTIVELY}

As this begins in the Nursery group in the Cerebral Palsy school where the ages range from two years, often much time has to be spent in frrst arousing the child to an awareness of its environment, and stimulating active participation before any activity will be productive. In the Nursery group and Kindergarten, the objectives of the programme are to develop language and the need to perceive, comprehend, discriminate, remember, perceive relationships, reason and be able to transfer what has been learned in one situation to a similar situation, or to make necessary modifications. The activities of the Kindergarten in training perception must emphasize appreciation of spatial rekationships, discrimination of figure-background and accurate recall of figure outlines, and the ability to reproduce these. It is at this stage, where pictorial representation of the concrete object is developed that further. individual difficulties may be found, such as the inability of the child to reproduce on paper what he sees. The programme must always be graded, augmented and intensified to meet the specific needs of each child.

The following are examples of activities to develop perception in the Nursery group and Kindergarten.

\section{NURSERY GROUP - DEVELOPMENT OF PERCEPTION}

A-Visual

1.-Specific Concrete Activities

Sorting blocks, buttons and sticks into boxes. Colour training.

Montossori Sense Training apparatus.

Play with plasticine and dough, water play, sand trays, paper mache moulding.

(The sense of touch developed through these activities is invaluable to the child with visual perception difficulties, as it is through touch 
and colour that he learns to discriminate shape)

Threading beads - putting colours together or grouping the different shapes.

\section{Finger Painting}

Potatoe cutouts.

Puzzles. The use of these is important. Cut a simple picture into pieces, having first discussed the picture with the child, and then let the child put it together again. Draw the trunk of a man - the child attaches legs, arms, and ears, and puts in the nose, eyes and mouth. A house is drawn and the child puts in windows and doors, etc.

\section{B-Spatial Concept}

Shallow and deep boxes - objects are taken out and put into these shallow and deep tins are filled with sand, Rods of different lengths are arranged. Big and small balls are used for play.

Instructions such as "go far away", "stand near the door", "sit together" etc. give a sense of space.

C-Auditory

Soft and loud music. Walk like elephants "tramp, tramp" and then like fairies, "pitter patter" - these activities to music. Percussion band. The child plays with tins filled with different objects and listens as he shakes. When the teacher shakes the tin, he tries to imitate the sound and names what is in the tin. Sounds made by animals and things with which the child is familiar, e.g. ear, water, drum, etc.

Training in sound sequence is developed by the child listening to sounds and saying which he heard first or last, helped by association with concrete objects placed first and last. For example, when dramatising a story such as the "Three Bears" - father's gruff voice is heard first, then mother's medium pitched voice and finally baby bear's "teeny.weeny" voice.

\section{FURTHER DEVELOPMENT OF PERCEPTION IN THE KINDERGARTEN}

A-Visual

1. Filling geometric shapes into spaces (trial and error method should be discouraged and the child should be made to feel the shapes).

2. Matching shapes. For the child who finds this difficult, colour-cue is used e.g. all squares blue, circles red, etc.

3. Matching shapes drawn on cards; this entails figure-background discrimination. If the child is unable to recognize a shape drawn against a background, then the "space" is coloured to help the shape stand out.

4. Matching cards on which patterns made up of strokes, circles, etc. are drawn.

5. Puzzles. Pictures are discussed, cut up and put together again. (This develops appreciation of the whole made up of the parts).

6. Letters of the alphabet assorted - the child does not know them as letters.

7. Matching pairs of words and also matching similar words.

\section{$B$-Auditory}

This continues to be ideveloped through singing; listening to sounds, e.g. the motor car passing, click of a typewriter, birds singing, voices in the street. Also, the child supplies missing rhyming words, and in addition the following activities are used:-

1. The child "looks, says and listens." He then sorts the pictures into groups of like sounds e.g. jam, lamb, pram, and coat, boat, goat; bee, sea, key.

2. He "looks, says and listens" and picks out the odd picture e.g. sun, run, pan; skip, bill, table.

3. Listens to the words sun, sit, sell and rubs, lips, bus and then says in which group he heard the "s" first or last.

\section{C-Spatial Concept}

This is further developed in the handwork and drawing class as "writing readiness," which is an essential part of "reading readiness." Directional training, making of patterns in clay, trays with plasticine, sticks, coloured wool, etc., and finally on paper, develops perception of spatial organization and the child learns to perceive form with under. standing. This process of analyzing wholes into parts before putting together again, is essential for the Cerebral Palsied child who cannot spontaneously reproduce on paper what he sees. It is olear that for the Cerebral Palsied child writing entails far more than merely developing motor patterns.

Thus far, the programme will have been based on concrete and semi-concrete activities in which a great variety of materials were used, the importance of which is stressed by Strauss and Lehtinen who maintain that materials are construeted to dramatize or concretize a process of skill clear of everything but the basic essentials and that they provide a crutch until skill and understanding are secure (1. p.137).

The child should, by the end of the Kindergarten training, be organised in his approach to tasks, be able to match words (which to him are at this stage just shapes), and have developed 
perception of sounds, and be able to recognize, recall and reproduce concrete shapes.

\section{GRADE I}

Here the reading readiness programme is based on developing finer vnsual and auditoryory discrimination through activities which lead to a real understanding of word components.

\section{VISUAL, DISCRIMINATION}

In the drawing and handwork lessons the child continues the directional training e.g. up, down, curve to the right, to the left, slanting down to the left; and further concepts, such as shallow, deep, tall, etc, are developed. Squares, triangles, circles, diamonds, ovals, etc. are built up making the child more aware of spatial organization; part whole relationships and visual discrimination is increased. Simple representations of e.g. cars, birds, bunnies, flowers, egg-cups, etc. composed of lines, curves, etc. are built up using plasticene, coloured gummed paper, feltex and are finally drawn by the child. For example, when drawing the flower - the child makes a curve to the top, right, left and bottom, makes a circle in the centre and a curved stem.

The children love these activities and the following is also thoroughly enjoyed. A pattern of shapes, i.e., circles, squares, triangles, strokes, half-moons etc. is built up on the flannel board, left there for a minute or two, then removed. The child must then reproduce this pattern in his book. The importance of this with regard to retaining a mental picture for later word recognition is obvious. Letlers of the alphabet - to the child the letters are still merely abstract shapes - are also built up on the flannclgraph and then reproduced.

\section{AUDITORY DISCRIMINATION}

This is further developed by training the child to listen to first, last and middle sounds. At first, the sounds given have an association such as toot (motor-car), boom (gun), tweet (bird), to help the child remember the sequence, especially when there is an auditory perception difficulty. Then abstract sounds with no association are introduced, e.g. s, br, m. Other activities are: giving words beginning with the same sound; blending sounds together as "s" and " $t$ "; " $h$ " and " $a$ "; separating the sounds when the teacher gives a "double" one as "sw." The pattern game is played but this time the teacher "says" a pattern i.e. she says "circle, square, stroke", etc., and the child draws what he heard the teacher say.
The child who can now discriminate, visually and auditorally, with understanding and reproduce abstract symbols, is ready to relate sounds to their visual symbols - i.e. ready for reading.

\section{READING PROGRAMME}

The children are told that they are going to make their own reading books. Large unlined scrap books are used and only three or four words written on a page. Unlined books are used as there is less figure-background confusion than in the ordinary lined books. In the initial stages of the programme only three letter-words are used.

Word recognition: A varied group of words with pictures are written in the books and flashcards of words and pictures made for each child are used. The words and pictures are matched with those in the book, then without the book and finally the words are used on flashcards alone.

(The use of manipulative apparatus helps to reduce distractibility; increases concentration, enables the child to proceed at his own rate and develops interest and a sense of responsibility as the child works with and looks after his own cards.)

\section{Artistic Bookbinders}

TRANSVALIA BUILDINGS

21 STIEMEN'S \& MELL STREET

Braamfontein - Phone 44-6584

Shop 8 in Melle Street.

HOW IMPORTANT ARE YOUR

it JOURNALS OF SPEECH AND

HEARING DISORDERS

is "SPEECH"

it NOTES

You can have these bound in attractive volumes to suit your needs.

We specialize in binding your thesis according to your design and colour schemes to insure your success. 
Sound Recognition. Two groups of words are given and the child gives the initial sound for each group. The picture of the words e.g. sun, sit, sip, are drawn and also for run, rat, rib. Picture cards are made and the child puts them in their respective "s house" and "r house" - he has to say the word himself and listen for sounds. A third and fourth group of wonds are given with the "s" and " $r$ " sounds at the end of the word and the same procedure is followed.

Sounds have Shapes. The words are written next to the pictures in the books, and the child looks for the matching symbols in the given words, and thus discovers the symbol for the sound. The symbol is drawn on a chart with a picture representing the sound e.g. picture of a snake with the $\mathrm{S}$. The words and pictures are used in the same manner as in "Word Recognition" described above. The child with visual or auditory perception difficulties is helped to remember the shape of the symbol $\mathrm{S}$ because of the association with a picture and appreciation of the fact that the first symbol is the first sound heard. The child with no speech is able to show his ability to recognize symbiols and words by matching them with the pictures.

\section{Recognition and Making of Shapes}

The child at this stage is able to recognize, recall and produce concrete known objects. Now he will have to recognize, as well as recall and reproduce, abstract symbols. A concrete association must be formed, niot only to help recall and reproduce the symbol, but also to recognize and recall the sound for the symbol. The following example shows how this is achieved. The child has related the sound " $b$ " with the symbol in his reading book. The picture of a bat and a ball is associated with the symbol and the initial sound of "bat" and "ball" is $b$. When writing the letter, the child says "bat" first, and then he says "ball" and so draws first a straight stroke representing bat and then draws a ball. This method prevents confusion of similar letters and reversals when writing and helps recognition of letters and sound recall.

Word Building: When the child knows the sounds used in the first few groups of words, they are used to complete words. For example, the picture of the sun is drawn and next to it -un, is written. Pictures of a rat with -at and bus with bu- next to the picture are also used. The missing sounds are supplied by the child.

The above procedure as from "Word Recognition" is repeated till all the consonants are known.
I have found that by the time about ten consonants have been learned the child knows vowel sounds as well, and through constantly seeing and saying the words with the vowel in the middle, they have no difficulty in filling in the missing sound when given the picture and the word.

When the child can recognize a number of words, a sentence describing a picture is written in the reader, e.g. the cat sits on a box in the sun. The sentence is written on cardboard, cut up into words and the child builds it up again.

\section{Word Building}

The child now "builds" or spells the words by saying the word and writing the sounds in the sequence they are heard. With the complete understanding of sound sequence the child is able to write any three letter-word.

Double letter sounds are learnt in the same way as the consonants and vowels i.e. by introducing the double soung e.g. "st" at the beginning and end of the words and then the middle sounds such as "ea," "ee" etc. (Words and pictures used.)

The Story: The child colours in a simple picture and pastes it in his reader, and tells the teacher what to write. The child then "reads" the story. (Only known words are used). Finally the child chooses a picture, pastes it in his book and writes his own story. He really has achieved a "reader" of his own.

In conclusion, I would like to point out that in the Cerebral Palsy class one often finds such children, as the aphasic child, the hard-of-hearing child, etc., each of whom presents their own particular difficulties and for whom more specially modified programmes must be adapted.

This programme evolved at the Johannesburg School and Treatment Centre for Cerebral Palsied Children is based on a long term policy of study and much trial and error. The positive results obtained have encouraged us to continue on these lines, and we hope that this article will be of help to others confronted with the problems of Cerebral Palsy or other fields in which the above suggestions are applicable and useful.

\section{REFERENCES}

(1) Strauss and Lehtinen: "Brain Injured Child. Vol 1.

With acknowledgement to the Principal and Management Committee of the Johannesburg School and Treatment Centre for Cerebral Palsied Children. 